\title{
Determination of Methemoglobin in Hemoglobin Submicron Particles Using NMR Relaxometry
}

\author{
Waraporn Kaewprayoon ${ }^{1,2}$, Nittiya Suwannasom ${ }^{1,3}{ }^{(\mathbb{D}}$, Chiraphat Kloypan ${ }^{1,4}{ }^{(}$, Axel Steffen ${ }^{1}(\mathbb{D}$, \\ Yu Xiong ${ }^{1}$, Eyk Schellenberger ${ }^{5}$, Axel Pruß ${ }^{1}$, Radostina Georgieva ${ }^{1,6}{ }^{\circledR}$ and \\ Hans Bäumler 1,* \\ 1 Charité-Universitätsmedizin Berlin, Institute of Transfusion Medicine, 10117 Berlin, Germany; \\ waraporn.kpy@gmail.com (W.K.); nittiya.su@up.ac.th (N.S.); chiraphat.kl@up.ac.th (C.K.); \\ Axel.steffen@charite.de (A.S.); Yu.Xiong@charite.de (Y.X.); axel.pruss@charite.de (A.P.); \\ radostina.georgieva@charite.de (R.G.) \\ 2 Department of Pharmacy, Payap University, Chiang Mai 50000, Thailand \\ 3 Division of Biochemistry and Nutrition, School of Medical Sciences, University of Phayao, \\ Phayao 56000, Thailand \\ 4 Division of Clinical Immunology and Transfusion Sciences, School of Allied Health Sciences, \\ University of Phayao, Phayao 56000, Thailand \\ 5 Charité-Universitätsmedizin Berlin, Institute of Radiology and Children Radiology, 10117 Berlin, Germany; \\ eyk.schellenberger@charite.de \\ 6 Department of Medical Physics, Biophysics and Radiology, Faculty of Medicine, Trakia University, \\ 6000 Stara Zagora, Bulgaria \\ * Correspondence: hans.baeumler@charite.de; Tel.: +49-(30)-45052-5131
}

Received: 30 October 2020; Accepted: 23 November 2020; Published: 26 November 2020

\begin{abstract}
Methemoglobin $(\mathrm{MetHb})$ is a hemoglobin $(\mathrm{Hb})$ derivative with the heme iron in ferric state $\left(\mathrm{Fe}^{3+}\right)$, unable to deliver oxygen. Quantification of methemoglobin is a very important diagnostic parameter in hypoxia. Recently, novel hemoglobin microparticles (Hb-MP) with a narrow size distribution around $700 \mathrm{~nm}$, consisting of cross-linked $\mathrm{Hb}$ were proposed as artificial oxygen carriers. The cross-linking of $\mathrm{Hb}$ by glutaraldehyde (GA) generates a certain amount of MetHb. Due to the strong light scattering, quantitative determination of MetHb in $\mathrm{Hb}-\mathrm{MP}$ suspensions by common spectrophotometry is not possible. Here, we demonstrate that ${ }^{1} \mathrm{H}_{2} \mathrm{O}$ NMR relaxometry is a perfect tool for direct measurement of total $\mathrm{Hb}$ and MetHb concentrations in $\mathrm{Hb}-\mathrm{MP}$ samples. The longitudinal relaxation rate $1 / \mathrm{T}_{1}$ shows a linear increase with increasing $\mathrm{MetHb}$ concentration, whereas the transverse relaxation rate $1 / T_{2}$ linearly increases with the total $\mathrm{Hb}$ concentration. In both linear regressions the determination coefficient $\left(R^{2}\right)$ is higher than 0.99 . The method does not require time-consuming pretreatment or digestion of the particles and is not impaired by light scattering. Therefore, it can be established as the method of choice for the quality control of $\mathrm{Hb}-\mathrm{MP}$ and similar hemoglobin-based oxygen carriers in the future.
\end{abstract}

Keywords: methemoglobin; hemoglobin microparticles (Hb-MP); ${ }^{1} \mathrm{H}_{2} \mathrm{O}$ NMR-relaxometry; hemoglobin-based oxygen carriers

\section{Introduction}

Hemoglobin $(\mathrm{Hb})$, the main component of red blood cells (RBC), is an iron-containing oxygen-transporting metalloprotein. It contains four heme groups each incorporating an iron atom in the ferrous state $\left(\mathrm{Fe}^{2+}\right)$, which can reversibly bind molecular oxygen $\left(\mathrm{O}_{2}\right)$, resulting in two states of $\mathrm{Hb}$ - the oxygenated $\mathrm{Hb}(\mathrm{OxyHb})$ and the deoxygenated $\mathrm{Hb}$ (DeoxyHb). In this way, RBC are loaded with $\mathrm{O}_{2}$ in the lung $(\mathrm{OxyHb})$ and $\mathrm{O}_{2}$ is delivered to the organs/tissue (DeoxyHb) [1,2]. In contrast 
to these two $\mathrm{Hb}$-states, $\mathrm{Hb}$ derivatives are altered forms of hemoglobin, which are formed by the combination of different iron ligands in the heme or by the oxidation state of the iron. After oxidation, the iron in the heme group changes to the ferric state $\left(\mathrm{Fe}^{3+}\right)$ and $\mathrm{Hb}$ becomes methemoglobin $(\mathrm{MetHb})$. $\mathrm{MetHb}$ cannot bind or carry oxygen molecules since the sixth coordination position of iron is bound either to a water molecule or a hydroxyl group [3,4]. Furthermore, the presence of MetHb increases the affinity of the remaining $\mathrm{Hb}$ or heme groups to oxygen, which makes the oxygen release in the tissues more difficult [4,5]. Normally one to two percent of a person's $\mathrm{Hb}$ is MetHb [5]. A higher percentage, can be of genetic origin or caused by exposure to various chemicals $[3,6]$. Depending on the level of $\mathrm{MetHb}$ in the blood, it can cause health problems known as methemoglobinemia. Therefore, the MetHb concentration in blood is a very important diagnostic parameter in cases of hypoxia.

One of common methods of hemoglobin analysis in clinical laboratories are based on the so called multiple wavelength spectrophotometry (CO-oximetry) [7-10], which exploits the differences in the absorption spectra of $\mathrm{OxyHb}$, DeoxyHb, and $\mathrm{MetHb}$. Before measurement, $\mathrm{Hb}$ is released from the RBCs by hemolysis to avoid the light scattering by the cells.

Recently, novel hemoglobin microparticles (Hb-MP) have been developed and proposed as artificial oxygen carriers. The fabrication procedure was published under the abbreviation CCD-technique (Co-precipitation-Crosslinking-Dissolution) [11-13] that reflects the three main preparation steps: co-precipitation of $\mathrm{Hb}$ with $\mathrm{MnCO}_{3}$, crosslinking of $\mathrm{Hb}$ and dissolution of the $\mathrm{MnCO}_{3}$. The resulting particles consist of cross-linked $\mathrm{Hb}$ and show a narrow size distribution around $700 \mathrm{~nm}$. The particles were investigated spectrophotometrically to demonstrate their oxygenation and deoxygenation [11,14]. However, $\mathrm{Hb}-\mathrm{MP}$ cannot be lysed like RBC and a quantitative determination of $\mathrm{OxyHb}$, DeoxyHb, and MetHb by multiple-wavelength spectrophotometry is not possible due to the strong light scattering of the $\mathrm{Hb}-\mathrm{MP}$ suspensions. It is known, that the cross-linking of $\mathrm{Hb}$ by glutaraldehyde (GA) causes a certain amount of MetHb to arise [15]. Therefore, a quantitative measurement of the MetHb content of the $\mathrm{Hb}-\mathrm{MP}$ is very important in view of their potential application as an artificial blood substitute and alternatives to spectrophotometric measurements are needed.

In previous studies, the oxygen carrying capacity of the Hb-MP was used for the indirect determination of dyshemoglobin or nonfunctional hemoglobin. The oxygen released after oxidation of the $\mathrm{Hb}$ by cyanide was directly measured and related to the amount of functional $\mathrm{Hb}$ in the $\mathrm{Hb}-\mathrm{MP}[12,16]$. The difference between total $\mathrm{Hb}$ and functional $\mathrm{Hb}$ equals nonfunctional hemoglobin. However, this method does not allow a direct measurement of MetHb and presupposes $100 \%$ oxygenation of the $\mathrm{Hb}$ in the $\mathrm{Hb}-\mathrm{MP}$.

The water proton nuclear magnetic resonance $\left({ }^{1} \mathrm{H}_{2} \mathrm{O}\right.$ NMR) relaxometry could be a suitable method that can be used for quantification of the MetHb concentration directly by measuring the oxidative state of iron in the $\mathrm{Hb}-\mathrm{MP}$. The different oxidation state of the iron in MetHb means that MetHb has a different electronic configuration and, therefore, different paramagnetic properties compared to that of $\mathrm{Hb}$ [17]. This difference can be detected using NMR spectroscopy by measuring the ${ }^{1} \mathrm{H}_{2} \mathrm{O}$ NMR longitudinal relaxation time $\left(\mathrm{T}_{1}\right)$ and the transverse relaxation time $\left(\mathrm{T}_{2}\right)$ or the corresponding relaxation rates $\left(1 / T_{1}\right.$ and $\left.1 / T_{2}\right)$. Previous studies on methemoglobin concentrations in blood samples have shown comparable values obtained by NMR and multiples-wavelength spectrophotometry $[18,19]$ but the NMR method is not influenced by light scattering and does not require lysis of RBC. Additionally, NMR provides information on the molecular environment and therefore it would allow to investigate the influence of the GA crosslinking on the molecular structure of $\mathrm{Hb}$ in the $\mathrm{Hb}-\mathrm{MP}$.

The aim of this study was to demonstrate that the ${ }^{1} \mathrm{H}_{2} \mathrm{O}$ NMR relaxation rates can be used to determine the total $\mathrm{Hb}$ as well as MetHb content of $\mathrm{Hb}-\mathrm{MP}$, because multiple wavelength spectrophotometry cannot be applied. Therefore, the ${ }^{1} \mathrm{H}_{2} \mathrm{O}$ NMR relaxation times of $\mathrm{Hb}$ in $\mathrm{Hb}$-solutions and in vital $\mathrm{RBC}$ were measured at various $\mathrm{MetHb}$ concentrations to investigate the influence of different surroundings on their relaxation properties. The influence of the GA crosslinking on the ${ }^{1} \mathrm{H}_{2} \mathrm{O}$ NMR relaxation rates was investigated using GA cross-linked RBC and GA HSA-MP. Finally, 
$\mathrm{Hb}-\mathrm{MP}$ suspensions with different MetHb contents were prepared and the ${ }^{1} \mathrm{H}_{2} \mathrm{O}$ NMR relaxation rates were measured.

\section{Results and Discussion}

\subsection{NMR of Human Hb/MetHb Solutions and RBCs/MetHb-RBC Suspensions}

Figure 1 shows the relaxation rates $1 / T_{1}$ and $1 / T_{2}$ of $\mathrm{Hb}$ solutions and suspensions of intact RBCs depending on the MetHb concentration. It can be seen that both, the longitudinal as well as the transverse relaxation accelerate with increasing MetHb concentration. The increase of $1 / T_{1}$ with increasing $\mathrm{MetHb}$ concentration is roughly equivalent in $\mathrm{Hb}$ solutions and suspensions of intact $\mathrm{RBCs}$ (Figure 1A), whereas $1 / T_{2}$ increases much faster with the MetHb concentration in RBC suspensions (Figure 1B). This is in agreement with the results obtained by other groups [20-23].
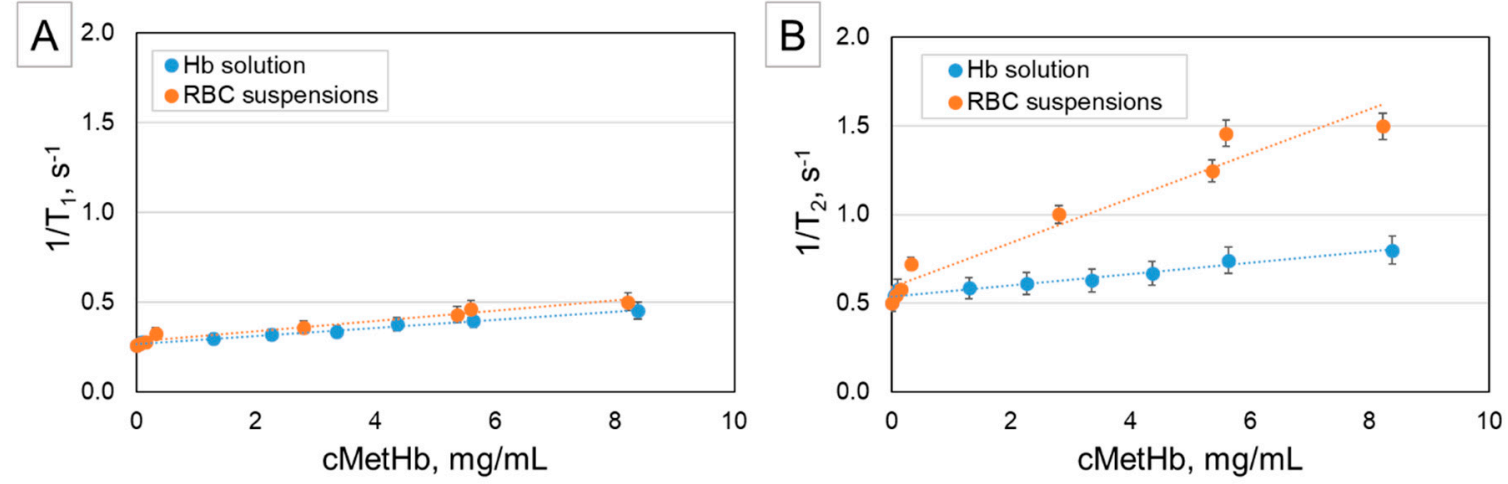

Figure 1. Relaxation rates $1 / \mathrm{T}_{1}(\mathbf{A})$ and $1 / \mathrm{T}_{2}(\mathbf{B})$ of $\mathrm{Hb}$ solutions and of $\mathrm{RBC}$ suspension as a function of the MetHb concentration (measured at proton frequency $40 \mathrm{MHz}$ and temperature $37^{\circ} \mathrm{C}$ ). The values represent means and standard deviations of $\mathrm{N}=6$ samples. The slopes of $1 / \mathrm{T}_{1}$ for $\mathrm{Hb}$ solutions $(0.0226)$ as well as for RBC suspensions (0.0287) are similar, but for $1 / \mathrm{T}_{2}$ the slopes are different $(0.0317$ for $\mathrm{Hb}$ solutions; 0.1254 for RBC suspensions).

The paramagnetic ${ }^{1} \mathrm{H}_{2} \mathrm{O}$ NMR relaxation of MetHb includes complex mechanisms with contributions from both the inner shell (bound water molecules) and outer shell (diffusional water molecules) [24-26]. Since all samples were prepared and processed under normal atmospheric conditions, $\mathrm{OxyHb}$ was the mean compound in the vital RBC obtained from the donor's blood. The electron configurations of the iron in $\mathrm{OxyHb}$ and $\mathrm{MetHb}$ are completely different. In $\mathrm{OxyHb}$ all electrons of the outer shell remain paired on lower energetic levels due to the strong ligand field of oxygen, whereas MetHb has five unpaired electrons. Additionally, the transformation of $\mathrm{Hb}$ to $\mathrm{MetHb}$ leads to a conformational change of the protein that opens the hydrophobic pocket normally protecting the iron in the heme from interaction with water. The unpaired electrons coupled with their accessibility by the water are behind the paramagnetic properties of $\mathrm{MetHb}$ and are directly responsible for the increase of $1 / T_{1}$ by proton-electron dipole-dipole interaction.

The direct paramagnetic effects of MetHb contribute also to $1 / \mathrm{T}_{2}$. This is visible in the slight increase of the transverse relaxation rate of $\mathrm{Hb}$ solutions with increasing MetHb content (Figure 1B). The much faster transverse relaxation in the intact RBC suspensions is caused by a diffusional mechanism. Here, the paramagnetic MetHb is concentrated inside the $\mathrm{RBC}$ and leads to a great difference of the magnetic susceptibility between the cell interior and the surrounding solution. Consequently, magnetic field gradients are generated within and around the RBC, influencing the protons of the water molecules diffusing across these gradients and causing $\mathrm{T}_{2}$ proton relaxation enhancement (PRE) [17]. Additionally, at the same total amount of $\mathrm{Hb}$ in the samples the concentration of $\mathrm{Hb}$ in the $\mathrm{RBC}$ is much higher than that in the $\mathrm{Hb}$ solutions impeding the Brownian movement of water. This so-called "water of hydration effect" also influences the transverse relaxation time [27]. 
Since bovine $\mathrm{Hb}$ is used for the fabrication of $\mathrm{Hb}-\mathrm{MP}$, the ${ }^{1} \mathrm{H}_{2} \mathrm{O}$ NMR relaxation behavior of bovine $\mathrm{Hb}$ solutions and bovine RBC suspensions were compared in one experiment and it was confirmed that they are not different (Supporting Information, Figure S2).

\subsection{NMR of RBCs Treated with GA (Influence of Crosslinking)}

In the fabrication of $\mathrm{Hb}-\mathrm{MP}$ a cross-linking step by GA is involved. GA randomly reacts with two amino groups of the proteins causing intramolecular or intermolecular bridges between the peptide chains [28,29]. It is known, that such chemical modifications lead to altered ${ }^{1} \mathrm{H}_{2} \mathrm{O}$ relaxation times due to changes in molecular weight, viscosity, chain flexibility, etc. [30]. In the case of $\mathrm{Hb}$ the reaction with GA is also connected with oxidation of the heme iron and formation of MetHb to some extent, which mainly depends on the applied GA concentration. Therefore, the influence of GA cross-linking on the ${ }^{1} \mathrm{H}_{2} \mathrm{O}$ relaxation rates was investigated in suspensions of RBCs cross-linked with different GA concentrations.

The results of these experiments are summarized in Figure 2. The relaxation rates $1 / T_{1}$ and $1 / T_{2}$ (Figure 2A,B, respectively) of RBC suspensions cross-linked with four different GA concentrations are plotted against the total $\mathrm{Hb}$ concentration $(\mathrm{cHb})$ in the samples. For comparison, the relaxation rates of native RBC ( $0 \% \mathrm{GA})$ are also shown. It can be seen that both relaxation rates have a linear dependency. The slopes of $1 / T_{1}$ and $1 / T_{2}$ calculated by regression analysis differ by a factor of 10 (tables in Figure 2), and represent $r_{1}$ and $r_{2}$, respectively, the so-called relaxivity. The slope of the longitudinal relaxation rate $1 / T_{1}$ increases with increasing GA concentration used for cross-linking, whereas the slope of the transverse relaxation rate $1 \mathrm{~T}_{2}$ reaches a maximum at a GA concentration around $0.1-0.2 \%$ and does not increase further. These relaxivities, $r_{1}$ and $r_{2}$, are presented in correlation with the GA concentration and the corresponding MetHb concentration on Figure 2C,D, respectively. It clearly demonstrates that $r_{1}$ or the longitudinal relaxation is dominated by the paramagnetic effect and therefore directly depends on the increasing $\mathrm{MetHb}\left(\right.$ or $\mathrm{Fe}^{3+}$ ) concentration. In contrast, $\mathrm{r}_{2}$ increases rapidly at low GA-concentrations and reaches a plateau at $0.1 \%$ GA.

$\mathrm{T}_{1}$ decreases with increasing GA concentration because the MetHb concentration increases correspondingly and $\mathrm{T}_{1}$ mainly reflects paramagnetic effects. In contrast, $\mathrm{T}_{2}$ decreases dramatically at very low GA-concentrations where the MetHb formation is lower than $20 \%$. This is due to the rapid increase of the degree of cross-linking already at low GA concentrations. At the same time, the dependency of $T_{2}$ on the paramagnetic effect of MetHb is very weak. This becomes evident at high GA concentrations, where MetHb increases dramatically but $T_{2}$ (and respectively $r_{2}$ ) are constant. When the cross-linking of all proteins is complete, $\mathrm{r}_{2}$ reaches a steady state and the paramagnetic effect of relaxation is dominated by the effect of the protein crosslinking [30-32].

\subsection{NMR of HSA-MP, Hb-MP, and MetHb-MP}

All particles used in this study were prepared by the CCD-technique [14] and GA was used for cross-linking (Table 1). The GA concentration applied for the fabrication of $\mathrm{Hb}-\mathrm{MP}$ was $0.02 \%$, as low as possible in order to minimize the oxidation of the heme iron and the generation of MetHb. HSA-MP were prepared with three concentrations of GA, including $0.02 \%$. These particles were used as a control of iron free protein particles to observe the effect of the cross-linking of the proteins.

The size of all particle types was in the range of $700-850 \mathrm{~nm}$. The narrow size distribution and the peanut like shape is visible in the scanning as well as in the transmission electron micrograms (Figure 3 ). $\mathrm{Hb}-\mathrm{MP}$ and MetHb-MP contained $22-24 \mathrm{mg} / \mathrm{mL} \mathrm{Hb}$ at a packed particle volume (PPV) concentration of $20 \%$. This is in agreement with previously reported values for Hb-MP [33]. The treatment with $\mathrm{NaNO}_{2}$ resulted in particles with more than $96 \% \mathrm{MetHb}$ (for simplicity these particles are referred as MetHb-MP). The content of $\mathrm{OxyHb}$ in the $\mathrm{Hb}-\mathrm{MP}$ and MetHb-MP was determined by the oxygen release method and was roughly $50 \%$ of the total $\mathrm{Hb}$ in the $\mathrm{Hb}-\mathrm{MP}$ and less than $4 \%$ in the MetHb-MP. 

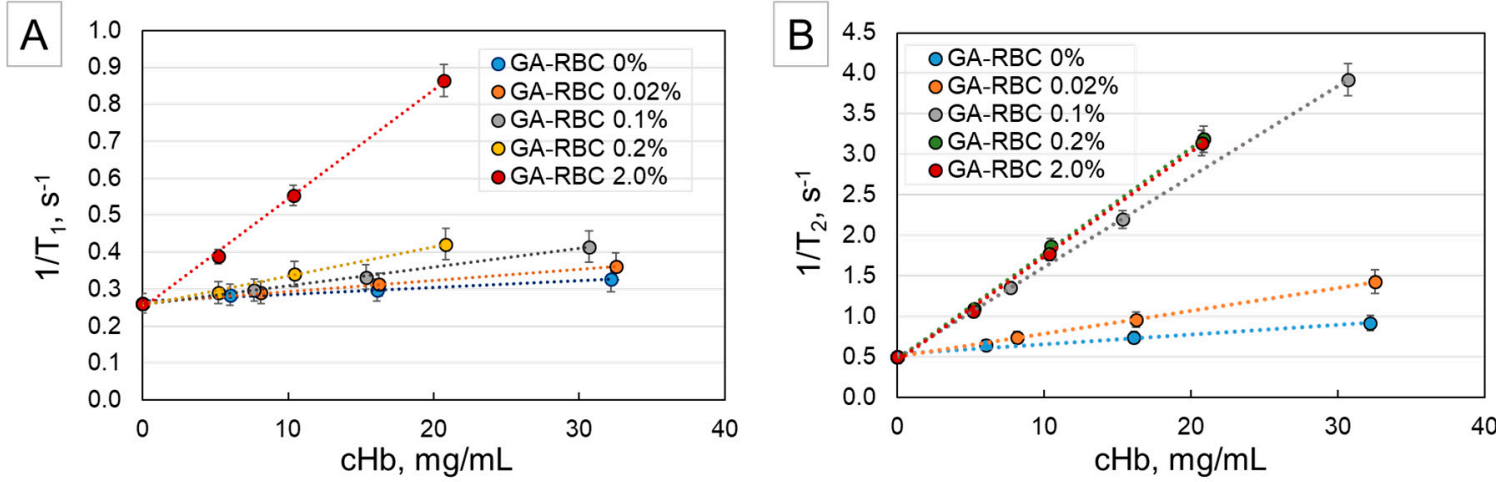

\begin{tabular}{l|c|c|c|} 
& \multicolumn{3}{|c}{ Regression: $1 / T_{1}=r_{1} \times c H b+B_{1}$} \\
\hline Sample & $r_{1}$ & $B_{1}$ & $R^{2}$ \\
\hline GA-RBC 0 \% & 0.0019 & 0.2671 & 0.9691 \\
\hline GA-RBC 0.02\% & 0.003 & 0.2635 & 0.9981 \\
\hline GA-RBC 0.1\% & 0.0050 & 0.2595 & 0.9983 \\
\hline GA-RBC 0.2\% & 0.0079 & 0.2571 & 0.9946 \\
\hline GA-RBC 2.0\% & 0.0295 & 0.2501 & 0.9982
\end{tabular}

\begin{tabular}{|c|c|c|c|}
\hline \multirow[b]{2}{*}{ Sample } & \multicolumn{3}{|c|}{ Regression: $1 / T_{2}=r_{2} \times c H b+B_{2}$} \\
\hline & $r_{2}$ & $\mathrm{~B}_{2}$ & $\mathrm{R}^{2}$ \\
\hline GA-RBC $0 \%$ & 0.0121 & 0.5385 & 0.9690 \\
\hline GA-RBC $0.02 \%$ & 0.0284 & 0.5059 & 0.9997 \\
\hline GA-RBC $0.1 \%$ & 0.1114 & 0.5007 & 1.0000 \\
\hline GA-RBC $0.2 \%$ & 0.1303 & 0.4747 & 0.9986 \\
\hline GA-RBC $2.0 \%$ & 0.1289 & 0.4529 & 0.9983 \\
\hline
\end{tabular}
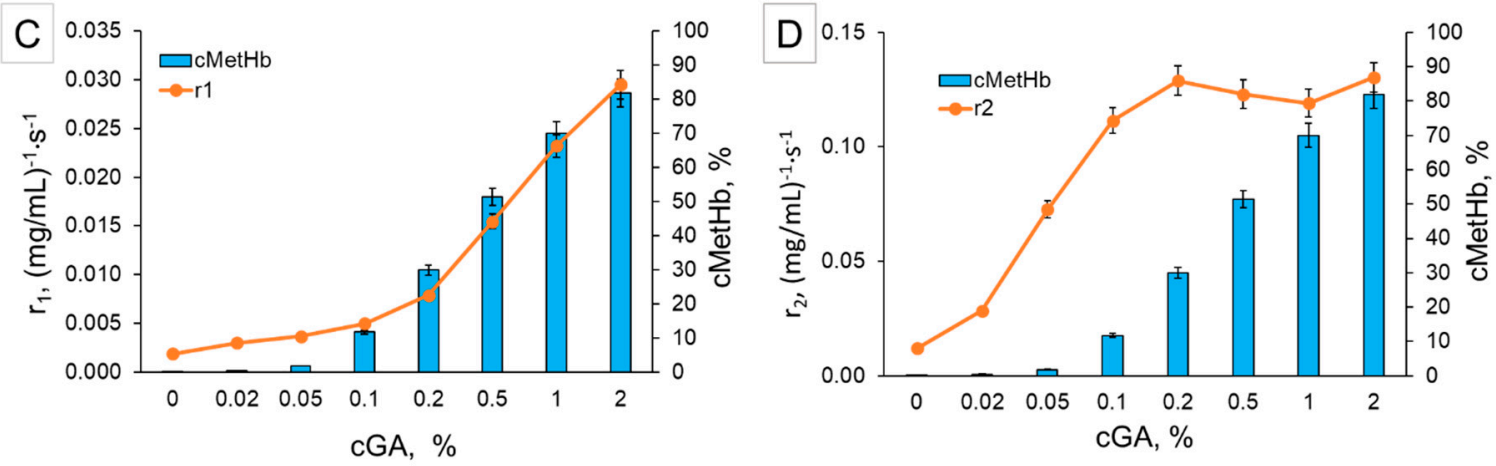

Figure 2. (A) Longitudinal relaxation rates $1 / T_{1}$ and (B) transverse relaxation rates $1 / T_{2}$ of $R B C$ suspensions treated with different GA concentrations depending on the total hemoglobin concentration. The results are fitted by a linear regression with the parameters shown in the tables below the corresponding graphs with $r_{1}$ and $r_{2}$ representing the slope (or the so called relaxivities), respectively. (C,D) Correlation between GA concentration, methemoglobin concentration (blue columns), and relaxivities $r_{1}$ and $r_{2}$ (orange curves), respectively. All measurements were performed at a proton frequency $40 \mathrm{MHz}$ and a preset temperature of $37^{\circ} \mathrm{C}$.

Table 1. Overview on the protein particles used in the ${ }^{1} \mathrm{H}_{2} \mathrm{O}$ NMR experiments $(\mathrm{N}=6)$.

\begin{tabular}{ccccccc}
\hline & & \multicolumn{5}{c}{ Values for Particle Suspensions with 20\% PPV } \\
\hline Type of MP & cGA & Size & $\begin{array}{c}\text { cHb } \\
\text { (by AHD) }\end{array}$ & $\begin{array}{c}\text { cFe } \\
\text { (ICP-OES) }\end{array}$ & $\begin{array}{c}\text { cOxyHb } \\
\left(\mathbf{O}_{2} \text { Release) }\right.\end{array}$ & $\begin{array}{c}\text { cMetHb } \\
\text { (cHb-cOxyHb) }\end{array}$ \\
\hline & $\%$ & $\mathbf{n m}$ & $\mathbf{m g} / \mathbf{m L}$ & $\mathbf{m g} / \mathbf{L}$ & $\mathbf{m g} / \mathbf{m L}$ & $\mathbf{m g} / \mathbf{m L}$ \\
\hline Hb-MP & 0.02 & $804.5 \pm 15.6$ & $22.9 \pm 3.3$ & $77.4 \pm 2.9$ & $11.4 \pm 0.5$ & $11.5 \pm 3.4$ \\
MetHb-MP & 0.02 & $809.2 \pm 15.4$ & $24.3 \pm 3.1$ & $82.5 \pm 4.7$ & $0.9 \pm 0.3$ & $23.4 \pm 5.0$ \\
\hline HSA-MP & 0.01 & $803.6 \pm 65.5$ & - & - & - & - \\
HSA-MP & 0.02 & $776.2 \pm 47.0$ & - & - & - & - \\
HSA-MP & 0.10 & $823.6 \pm 28.9$ & - & - & - & - \\
\hline
\end{tabular}




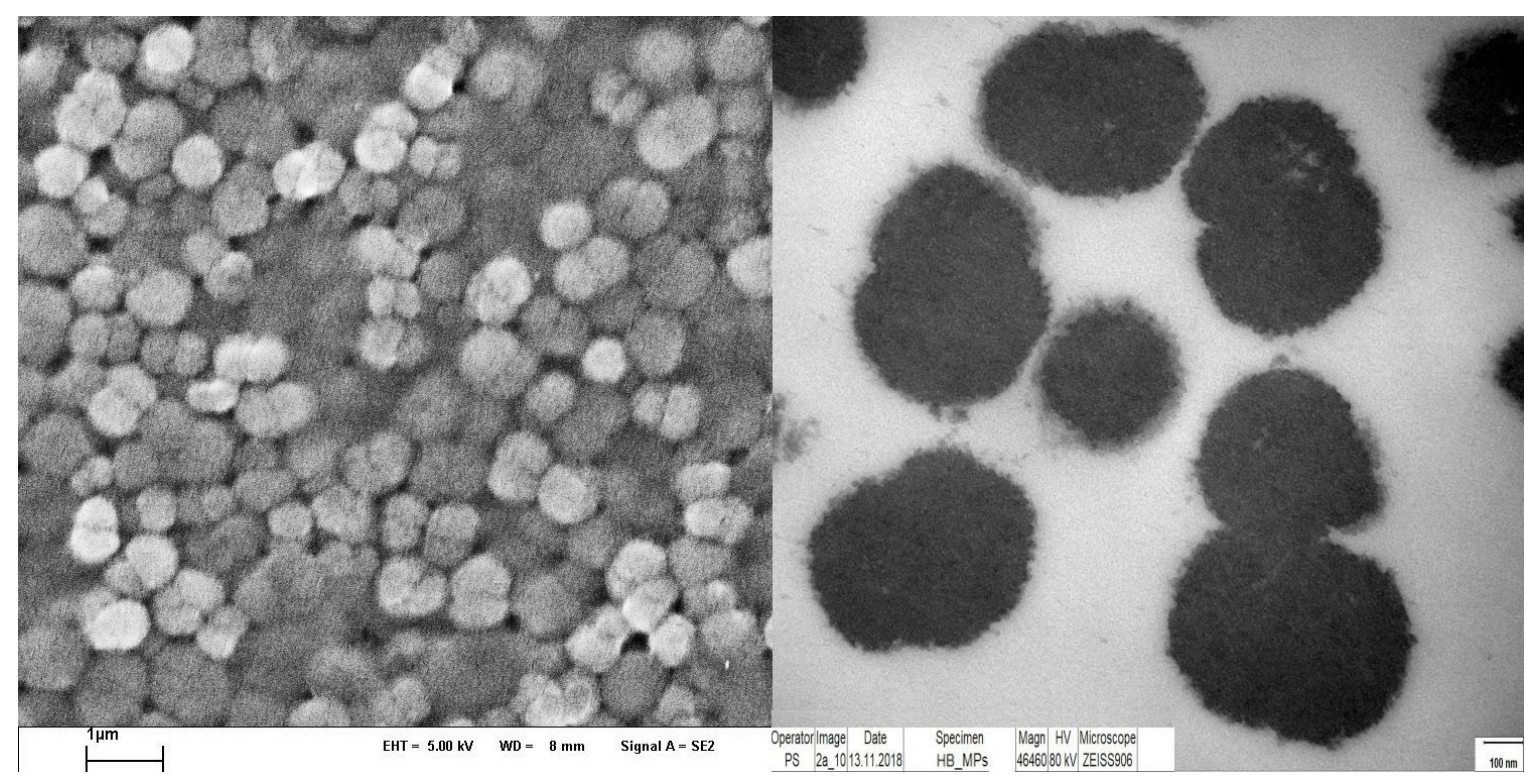

Figure 3. Scanning electron micrograph (left) of $\mathrm{Hb}-\mathrm{MP}$ as overview showing the uniform size distribution of the particles in the submicron size range. Transmission electron micrograph of $\mathrm{Hb}-\mathrm{MP}$ at higher magnification (right).

The graphs in Figure $4 A, B$ show the longitudinal relaxation rate $\left(1 / T_{1}\right)$ and the transverse relaxation rate $\left(1 / \mathrm{T}_{2}\right)$, respectively, of HSA-MP suspensions prepared with different concentrations of GA depending on the particle volume concentration (packed particle volume, PPV). In all samples, the relaxation rates linearly increase with increasing particle concentration. Since HSA-MP do not contain any paramagnetic element, the increase of the relaxation rates is only due to the increase of the protein amount in the samples. The slopes of the linear regressions (or relaxivities, $r_{1}$ and $r_{2}$ ) obtained for the samples prepared with $0.02 \%$ and $0.1 \%$ GA are practically equal. However, they are much higher than that obtained for the sample with $0.01 \% \mathrm{GA}$. This means that already at a GA-concentration of $0.02 \%$, the formation of the protein cross-linked network is completed and therefore higher GA concentration does not contribute to structural changes in the molecular structure of the particles.

$\mathrm{Hb}-\mathrm{MP}$ and MetHb-MP were prepared with $0.02 \%$ GA and presumably, the protein cross-linking is completed and should not influence the relaxation rates. In Figure $4 \mathrm{C}, \mathrm{D}$ the $1 / \mathrm{T}_{1}$ and $1 / \mathrm{T}_{2}$ of HSA-MP, $\mathrm{Hb}-\mathrm{MP}$, and MetHb-MP suspensions, prepared with $0.02 \%$ GA depending on the particle volume concentration (PPV) are presented. The results are fitted by a linear regression with the parameters shown in the tables below the corresponding graphs. Both relaxivities are enhanced in comparison with the respective relaxivities of the HSA-MP, which corresponds to the presence of the heme iron. The longitudinal relaxivity, $\mathrm{r}_{1}$, of MetHb-MP is twice as high as that of the $\mathrm{Hb}-\mathrm{MP}$ because more than $96 \%$ of the iron is in the paramagnetic $\mathrm{Fe}^{3+}$ state. In contrast, the transverse relaxivity, $\mathrm{r}_{2}$, of MetHb-MP is not very different from that of the $\mathrm{Hb}-\mathrm{MP}$, because the cross-linking of the proteins is completed and the paramagnetic effect of MetHb has no influence on $\mathrm{T}_{2}$. It has to be noted that the GA concentration necessary to complete the protein cross-linking in the particles is roughly five times lower than that needed to achieve the same effect in RBC $(0.02 \%$ for all investigated particles and $0.1 \%$ for RBC). However, the exact calculation of the ratio of GA to protein in both cases is difficult since both systems are very different. Additionally, the permeability of the RBC membrane and the cross-linking of the membrane proteins may contribute to this difference. 

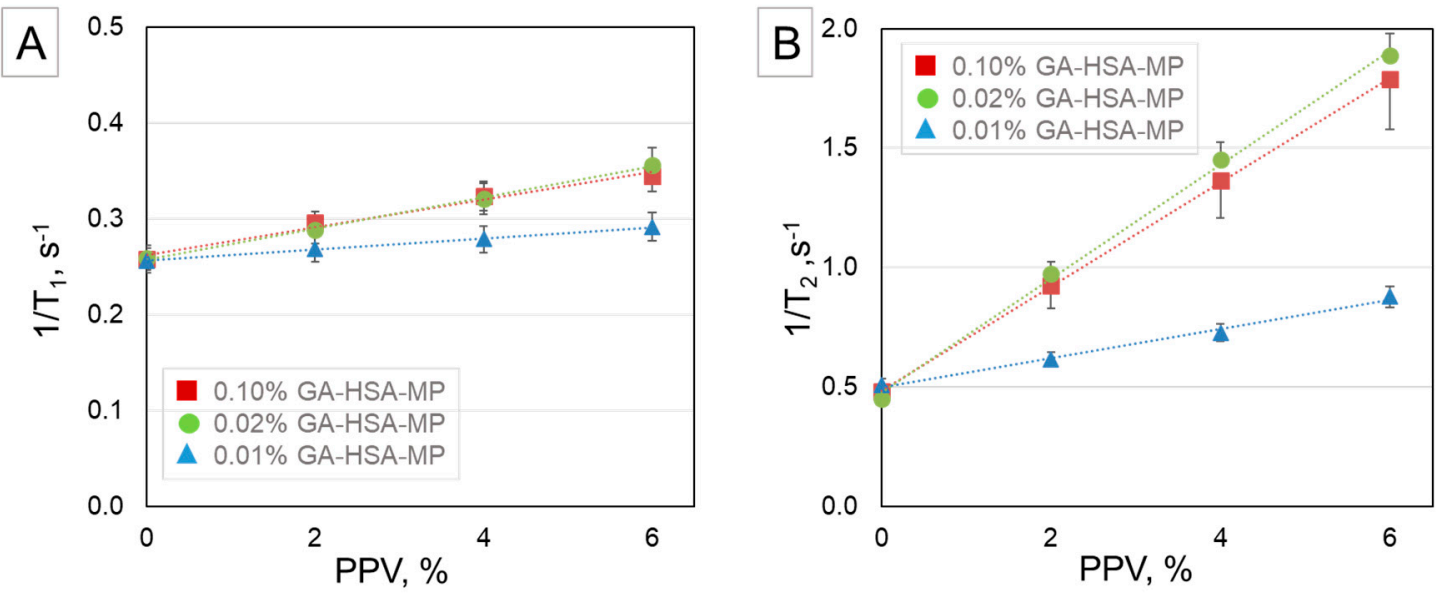

\begin{tabular}{c|c|c|c|} 
& \multicolumn{3}{|c}{ Regression: $1 / T_{1}=r_{1} \times P P V+B_{1}$} \\
\hline GA \% & $r_{1}$ & $B_{1}$ & $R^{2}$ \\
\hline 0.01 & 0.0058 & 0.2563 & 0.9983 \\
\hline 0.02 & 0.0161 & 0.2575 & 0.9983 \\
\hline 0.10 & 0.0144 & 0.2624 & 0.9983 \\
\hline
\end{tabular}
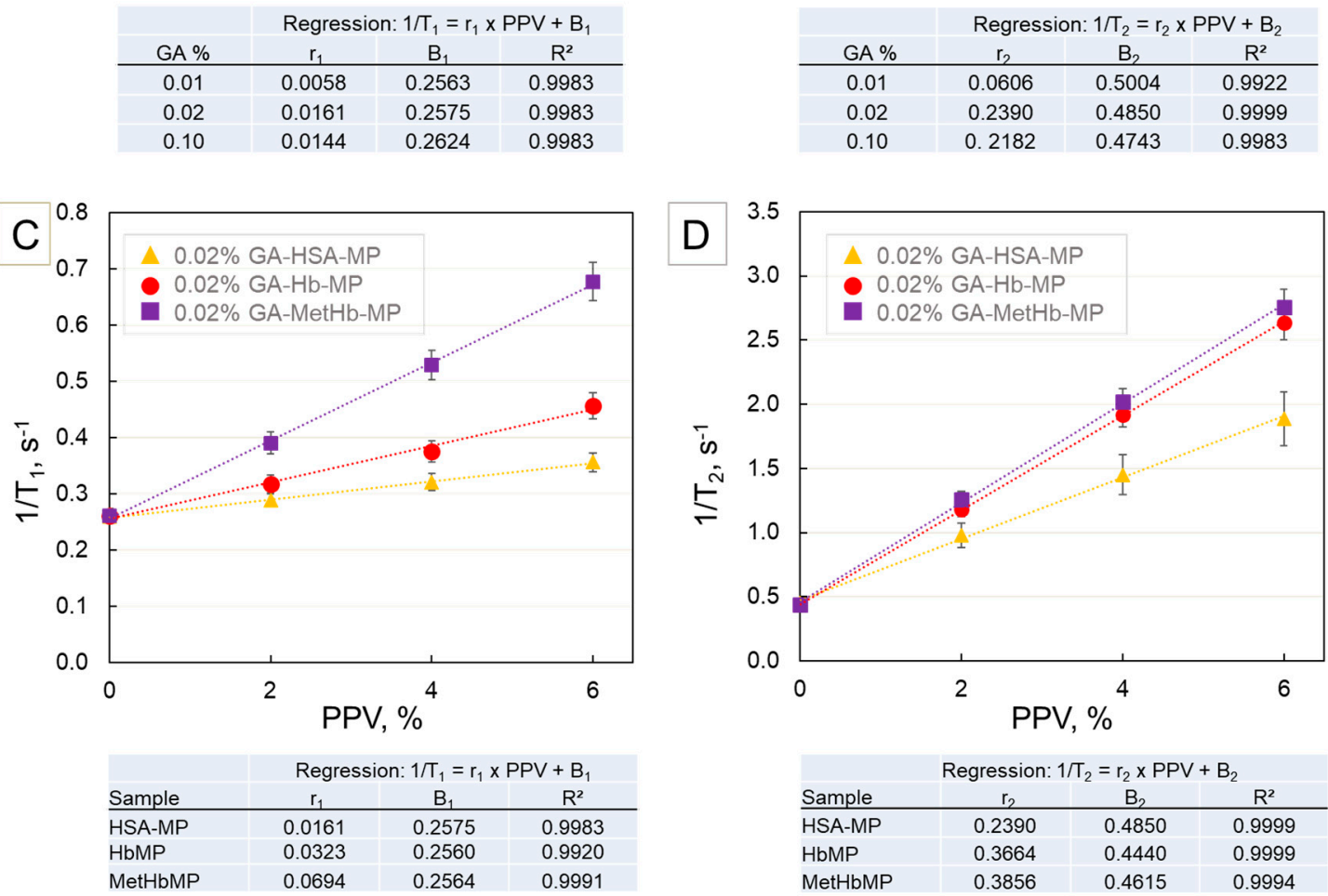

Figure 4. Relaxation rates of HSA-MP suspensions prepared with different concentrations of GA depending on the particle volume concentration (PPV). (A) Longitudinal relaxation rate $\left(1 / \mathrm{T}_{1}\right)$ and $(\mathbf{B})$ transverse relaxation rate $\left(1 / \mathrm{T}_{2}\right)$. Comparison of $(\mathbf{C})$ longitudinal relaxation rate $\left(1 / \mathrm{T}_{1}\right)$ and $(\mathbf{D})$ transverse relaxation rate $\left(1 / \mathrm{T}_{2}\right)$ of HSA-MP, Hb-MP, and MetHb-MP suspensions, prepared with $0.02 \%$ GA depending on the particle volume concentration (PPV). The parameters applied for the linear regressions are shown in the tables below the corresponding graphs. Results were obtained at a proton frequency $40 \mathrm{MHz}$ and temperature $37^{\circ} \mathrm{C}$.

\subsection{NMR as a Tool for Determination of Total $\mathrm{Hb}$ and MetHb in $\mathrm{Hb}-\mathrm{MP}$}

We mixed $\mathrm{Hb}-\mathrm{MP}$ and MetHb-MP suspensions (prepared with $0.02 \% \mathrm{GA}$ ) at the ratios 100/0, 80/20, 60/40, 40/60, 20/80, and 0/100 and diluted them with PBS to obtain suspensions with final PPV of $2 \%, 4 \%$, and $6 \%$. The total $\mathrm{Hb}$ concentration $(\mathrm{cHb})$ and the MetHb concentration (cMetHb) in the mixtures were calculated using the data for the $\mathrm{Hb}-\mathrm{MP}$ and the MetHb-MP in Table 1.

The obtained relaxation rates $1 / T_{1}$ and $1 / T_{2}$ of all mixtures and dilutions were plotted against $\mathrm{cMetHb}$ (Figure 5A,B, respectively) and $\mathrm{cHb}$ (Figure 5C,D, respectively). It can be seen that the longitudinal relaxation rate $1 / \mathrm{T}_{1}$ shows a linear increase with increasing $\mathrm{cMetHb}$ (Figure $5 \mathrm{~A}$ ), 
whereas $1 / \mathrm{T}_{2}$ linearly depends on $\mathrm{cHb}$ (Figure $5 \mathrm{D}$ ). In both cases the data are fitted by a linear regression with a determination coefficient $\left(R^{2}\right)$ higher than 0.99 .
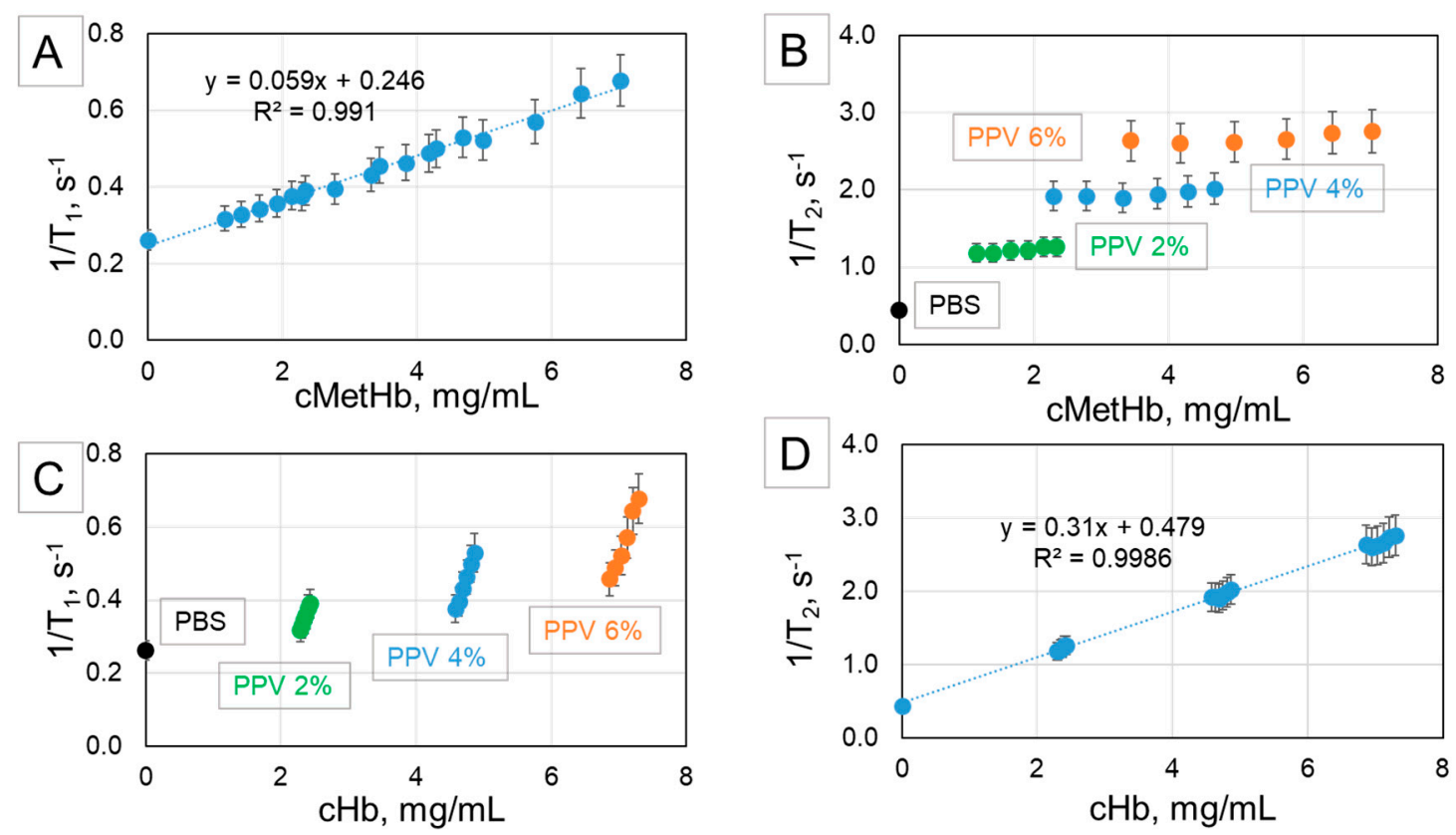

Figure 5. Relaxation rates of $\mathrm{Hb}-\mathrm{MP} / \mathrm{MetHb}-\mathrm{MP}$ mixed suspensions prepared with $0.02 \%$ GA. $\mathrm{Hb}-\mathrm{MP}$ and MetHb-MP are mixed at ratios 100/0, 80/20, 60/40, 40/60, 20/80, and 0/100 and diluted to obtain suspensions with PPV of $2 \%, 4 \%$, and $6 \%$. (A) Longitudinal relaxation rate $\left(1 / \mathrm{T}_{1}\right)$ and (B) transverse relaxation rate $\left(1 / \mathrm{T}_{2}\right)$ depending on the MetHb concentration in the suspensions. (C) Longitudinal relaxation rate $\left(1 / \mathrm{T}_{1}\right)$ and $(\mathrm{D})$ transverse relaxation rate $\left(1 / \mathrm{T}_{2}\right)$ depending on the total $\mathrm{Hb}$ concentration. The measurements were performed at a proton frequency of $40 \mathrm{MHz}$ and a preset temperature of $37^{\circ} \mathrm{C}$.

As expected, $1 / \mathrm{T}_{2}$ is not influenced much by the MetHb content. As seen in Figure $5 \mathrm{~B}$, the values for the transverse relaxation of mixed suspensions with the same PPV are not different. In contrast, the longitudinal relaxation rate of mixed suspensions with the same PPV is strongly dependent on the ratio $\mathrm{Hb}-\mathrm{MP} / \mathrm{MetHb}-\mathrm{MP}$ as it is demonstrated in Figure $5 \mathrm{C}$, where $1 / \mathrm{T}_{1}$ is plotted against the total $\mathrm{Hb}$ concentration.

In conclusion, we could confirm the linear increase of $1 / \mathrm{T}_{1}$ and $1 / \mathrm{T}_{2}$ as a function of the MetHb concentration in $\mathrm{Hb}$ solutions and RBC suspensions as already shown by other studies. The much faster increase of $1 / \mathrm{T}_{2}$ in suspensions of intact RBC is explained by the unequal distribution of $\mathrm{Hb} / \mathrm{MetHb}$ between cell interior and surrounding solution. Consequently, the generated magnetic field gradients within and around the RBC lead to relaxation enhancement caused by the diffusion of water across them. The so-called "water of hydration effect" caused by the impeded Brownian movement of water contributes also to the faster transverse relaxation in RBC suspensions.

The results obtained for suspensions of RBCs cross-linked with different GA concentrations revealed that the longitudinal and the transverse relaxation behavior deliver information on the two different aspects of the GA cross-linking: (i) degree of iron oxidation and MetHb generation via longitudinal relaxivity $\mathrm{r}_{1}$ and (ii) degree of cross-linking and protein network formation via transverse relaxivity $r_{2}$, respectively. Additionally, the measurements of HSA-MP confirmed that the degree of network formation mainly influences the transversal relaxation. These results were very important for the interpretation of the data obtained for $\mathrm{Hb}-\mathrm{MP}$.

Finally, the measurements performed with $\mathrm{Hb}-\mathrm{MP}$ and MetHb-MP confirmed that ${ }^{1} \mathrm{H}_{2} \mathrm{O}$ NMR is a perfect tool for investigation of $\mathrm{Hb}$-MP samples by direct measurement of their total $\mathrm{Hb}$ (using the transverse relaxation rate, $1 / \mathrm{T}_{2}$ ) and $\mathrm{MetHb}$ (using the longitudinal relaxation rate $1 / \mathrm{T}_{1}$ ). The method 
does not require time-consuming pretreatment or digestion of the particles and is not impaired by light scattering like spectroscopic methods. Therefore, it can be established as the method of choice for the quality control of $\mathrm{Hb}-\mathrm{MP}$ and similar hemoglobin based oxygen carriers in the future.

\section{Materials and Methods}

\subsection{Materials}

Fresh human blood samples were collected from healthy volunteers in accordance with the transfusion law of Germany. Informed consent was obtained from all donors in written form. The use of donor blood samples for scientific purposes was approved by the ethics committee of Charité-Universitätsmedizin Berlin (\# EA1/137/14). The blood was withdrawn into K2 EDTA (1.8 mg/mL, EDTA) blood tubes, Becton Dickinson (BD), Heidelberg, Germany.

Fresh bovine whole blood (EDTA-anticoagulated) was obtained from Biophyll $\mathrm{GmbH}$, Dietersburg, Germany.

Phosphate buffered saline pH 7.4 (PBS pH 7.4) was purchased from Fisher bioreagents ${ }^{\circledR}$, Fisher Scientific, Hampton, NH, USA. Sodium nitrite $\left(\mathrm{NaNO}_{2}\right)$, glutaraldehyde $25 \%$ (GA), manganese chloride $\left(\mathrm{MnCl}_{2}\right)$, sodium carbonate $\left(\mathrm{Na}_{2} \mathrm{CO}_{3}\right)$, disodium ethylenediaminetetraacetate $\left(\mathrm{Na}_{2}\right.$-EDTA), potassium ferricyanide $\left(\mathrm{K}_{3}\left[\mathrm{Fe}(\mathrm{CN})_{6}\right]\right)$, sodium chloride $(\mathrm{NaCl})$, Triton-X-100, were purchased from Sigma-Aldrich $\mathrm{GmbH}$, Darmstadt, Germany.

\subsection{Preparation of Vital RBC, GA-Treated RBC (GA-RBC), and Sodium Nitrite Treated RBC (MetHb-RBC) Suspensions}

Immediately after blood collection, tubes were slowly agitated to ensure an appropriate mixing of anticoagulant. The blood samples were centrifuged at $2000 \times \mathrm{g}, 10 \mathrm{~min}, 4{ }^{\circ} \mathrm{C}$ to remove plasma and buffy coat and the isolated RBCs were washed three times with PBS pH 7.4. The washed RBCs were resuspended in PBS pH 7.4, the hematocrit (Hct) was measured and adjusted to 10\% (centrifugation at $20,000 \times g, 10 \mathrm{~min})$.

RBC suspensions with $10 \%$ Hct were incubated with $0.02 \%, 0.05 \%, 0.1 \%, 0.2 \%, 0.5 \%, 1.0 \%$, and $2.0 \% \mathrm{GA}$, respectively (room temperature $22{ }^{\circ} \mathrm{C}, 1 \mathrm{~h}$ ). After incubation, the GA-RBCs were washed five times with PBS pH 7.4 (centrifugation at $2000 \times g, 10 \mathrm{~min}, 4{ }^{\circ} \mathrm{C}$ ) to remove unbound GA and finally the initial volume of the suspension was reconstituted with $\mathrm{PBS} \mathrm{pH}$ 7.4. The total iron content (cFe) of the GA-RBC suspensions was measured by inductively coupled plasma optical emission spectroscopy (ICP-OES; Thermo, iCAP 6300 Duo, Thermo Fisher Scientific GmbH, Berlin, Germany). Before measurement the GA-RBCs were dissolved with $6 \mathrm{M} \mathrm{HCl}$. The values obtained for the total iron were used to calculate the total $\mathrm{Hb}$ concentration in the GA-RBC samples. The $\mathrm{COxyHb}$ concentration was determined indirectly by the oxygen release method as described below. The MetHb concentration was calculated as the difference between total $\mathrm{Hb}$ and $\mathrm{OxyHb}$.

Sodium nitrite $\left(\mathrm{NaNO}_{2}\right)$ reacts in aqueous millieu with $\mathrm{Fe}^{2+}$ of $\mathrm{Hb}$ oxidizing it to $\mathrm{Fe}^{3+}$ and therefore converting $\mathrm{Hb}$ to MetHb [34,35]. Native RBC suspensions (10\% Hct in PBS (pH 7.4)) were incubated with $5 \mathrm{mM} \mathrm{NaNO}_{2}$ under gentle mixing at room temperature $\left(22^{\circ} \mathrm{C}\right)$ for $30 \mathrm{~min}$ and were thereafter stored overnight at $4{ }^{\circ} \mathrm{C}$. The MetHb-RBCs were washed three times with PBS pH 7.4 at $2000 \times g, 10 \mathrm{~min}, 4^{\circ} \mathrm{C}$ and finally the RBC concentration was adjusted to $10 \%$ Hct with PBS, pH 7.4.

\subsection{Preparation of $\mathrm{Hb}$ and MetHb Solutions}

$\mathrm{Hb}$ solutions were prepared by lysing the RBCs with diluted PBS pH 7.4 at $100 \mathrm{mOsmol} / \mathrm{kg}$. The lysed RBCs were centrifuged at $10,000 \times g, 10 \mathrm{~min}, 4{ }^{\circ} \mathrm{C}$ to eliminate the cell membranes. The supernatant was collected and filtered through a membrane filter (pore size $0.2 \mu \mathrm{m}$; Carl Roth $\mathrm{GmbH}$, Karlsruhe, Germany). Total $\mathrm{Hb}$ concentration $(\mathrm{cHb})$ was measured using ABL700 (Radiometer ${ }^{\circledR}$, Copenhagen, Denmark) and adjusted to $30 \mathrm{mg} / \mathrm{mL}$ by dilution with PBS pH 7.4. 
MetHb solutions were prepared lysing MetHb-RBCs with diluted PBS (pH 7.4 at $100 \mathrm{mOsmol} / \mathrm{kg}$ ) as described for the $\mathrm{Hb}$ solution above.

\subsection{Determination of Oxyhemoglobin in RBC Suspensions and Hb Solutions}

Two approaches were applied for the determination of oxyhemoglobin $(\mathrm{OxyHb})$ in $\mathrm{RBC}$ suspensions and $\mathrm{Hb}$ solutions-a standard method using a blood gas analyzer (ABL700, Radiometer ${ }^{\circledR}$, Copenhagen, Denmark) and an indirect method based on measurement of the oxygen release after oxidation of the iron in the heme by $\mathrm{K}_{3}\left[\mathrm{Fe}(\mathrm{CN})_{6}\right][36,37]$. The results delivered by the two methods for $\mathrm{Hb}$ solutions and $\mathrm{RBC}$ suspensions correlated very well with each other (Supporting Information, Figure S1).

The optical system of ABL700 includes a 128-wavelength spectrophotometer connected via an optical fiber with a measuring chamber in which the blood sample is hemolyzed by ultra-sonication. The measurements were conducted in the wavelength range $478-672 \mathrm{~nm}$. The concentration of each compound is determined using the following equation:

$$
c_{y}=\sum_{y=1}^{128} K_{y}^{\lambda_{n}} A_{\text {total }}^{\lambda_{n}}
$$

where $A_{\text {total }}^{\lambda_{n}}$ is the total absorption of the sample measured at a certain wavelength $\lambda_{n}, K_{y}^{\lambda_{n}}$ are the constants specific to each compound at this wavelength.

In such a way the blood gas analyzer delivers data on the total $\mathrm{Hb}$ concentration $(\mathrm{cHb})$ and percentage of hemoglobin derivatives (mainly $\mathrm{OxyHb}$ and $\mathrm{MetHb}$ ).

The oxygen release measurement was performed using a miniaturized optical needle-type oxygen sensor (oxygen microsensor NTH-PSt7, PreSens, Regensburg, Germany) connected with a portable oxygen meter with data logging (Microx 4, PreSens-Precision Sensing GmbH, Germany). A total of $100 \mu \mathrm{L}$ of $\mathrm{Hb}$ solution $(30 \mathrm{mg} / \mathrm{mL}$ ) or $100 \mu \mathrm{L}$ of RBC suspension (Hct $10 \%$ ) were added into $900 \mu \mathrm{L} 0.1 \%$ Triton-X100 solution in PBS pH 7.4 and were stirred for $5 \mathrm{~min}$. After stabilization of the measured value for the oxygen concentration in the solution with one measuring point per second, $50 \mu \mathrm{L}$ of $10 \% \mathrm{~K}_{3}\left[\mathrm{Fe}(\mathrm{CN})_{6}\right]$ were added and the increase of the oxygen concentration in the solution is detected. The amount of $\mathrm{OxyHb}$ in the solutions can be calculated using Equations (2) and (3):

$$
\begin{gathered}
m \mathrm{O}_{2}(\mu \mathrm{g})=\left(c \mathrm{O}_{2 \text { start }} \cdot V_{\text {start }}\right)-\left(\mathrm{cO}_{2 \text { end }} \cdot V_{\text {end }}\right)\left[\frac{\mu g \cdot \mathrm{mL}}{\mathrm{mL}}\right] \\
c \mathrm{OxyHb}=\frac{m \mathrm{O}_{2}}{1.916} \cdot\left(\frac{1}{V_{\text {end }}}\right)
\end{gathered}
$$

with $\mathrm{cO}_{2 \text { start }}$ and $\mathrm{cO}_{2 \text { end }}$ being the concentrations of oxygen in the solution before and after the addition of $\mathrm{K}_{3}\left[\mathrm{Fe}(\mathrm{CN})_{6}\right]$, respectively, $V_{\text {start }}$ and $V_{\text {end }}$ initial and final sample volume, $\mathrm{mO}_{2}$ the mass of oxygen, and $1.916(\mathrm{mg} / \mathrm{g})$ the mass of oxygen $(\mathrm{mg})$, which is bound by one gram $\mathrm{Hb}$.

\subsection{Preparation and Characterization of Hemoglobin Microparticles (Hb-MP), Human Serum Albumin} Microparticles (HSA-MP), and Methemoglobin Particles (MetHb-MP)

$\mathrm{Hb}-\mathrm{MP}$ and HSA-MP were fabricated following a slightly modified CCD-method described by Xiong et al. [12,14,33]. Briefly, $20 \mathrm{~mL} \mathrm{Na}_{2} \mathrm{CO}_{3}(0.25 \mathrm{M})$ and $10 \mathrm{~mL} \mathrm{MnCl}_{2}(0.5 \mathrm{M})$ containing $0.5 \mathrm{~g} / \mathrm{dL}$ bovine $\mathrm{Hb}$ or HSA were rapidly mixed in a $100 \mathrm{~mL}$ beaker under vigorous stirring for $30 \mathrm{~s}$ at room temperature to produce the manganese carbonate protein-microparticles $\left(\mathrm{MnCO}_{3}-\mathrm{Hb}-\mathrm{MP}\right.$, $\mathrm{MnCO}_{3}$-HSA-MP). The carbonate-protein particles were separated by centrifugation at $3000 \times g, 4^{\circ} \mathrm{C}$ for 3 min followed by three washing steps with $\mathrm{NaCl} 0.9 \%$ solution. For crosslinking of the entrapped proteins, the $\mathrm{MnCO}_{3}-\mathrm{Hb}-\mathrm{MP}$ were incubated in a $0.02 \%$ GA solution and the $\mathrm{MnCO}_{3}-\mathrm{HSA}-\mathrm{MP}$ in $0.01 \%, 0.02 \%$, and $0.1 \%$ GA solutions, respectively, for $1 \mathrm{~h}$ at room temperature. Thereafter the $\mathrm{MnCO}_{3}$ 
templates were dissolved with $0.2 \mathrm{M} \mathrm{Na}_{2}$-EDTA solution ( $\mathrm{pH} 7.4$ ). Finally, the particles were washed three times with $0.9 \% \mathrm{NaCl}$ solution containing $0.2 \mathrm{~g} / \mathrm{dL} \mathrm{HSA}\left(10,000 \times \mathrm{g}, 4{ }^{\circ} \mathrm{C}, 10 \mathrm{~min}\right)$ and resuspended in PBS pH 7.4. The packed particle volume (PPV) in the suspension was adjusted to $10 \%$. The particle size was determined by dynamic light scattering (Zetasizer Nano ZS, Malvern Instruments Ltd., Malvern, UK). All measurements were performed in triplicate at $25^{\circ} \mathrm{C}$.

The total hemoglobin concentration in the Hb-MP was measured by a modified AHD-575 method as described before [12]. Briefly, Hb-MP suspensions (PPV $2 \%$ ) were digested by $0.5 \mathrm{mg} / \mathrm{mL}$ Pronase (Roche Diagnostics $\mathrm{GmbH}$, Mannheim, Germany) at $45^{\circ} \mathrm{C}$ for $30 \mathrm{~min}$. Then AHD reagent was added (volume ratio 1:1) and incubated for further $15 \mathrm{~min}$ at room temperature. Finally, the samples were centrifuged $(10,000 \times g$ for $10 \mathrm{~min})$, the supernatants were collected, and their absorption was measured using a UV-VIS spectrophotometer at $575 \mathrm{~nm}$ (Hitachi U2800, Hitachi High-Technologies Corporation).

The total iron content $(\mathrm{cFe})$ of the $\mathrm{Hb}-\mathrm{MP}$ was measured by inductively coupled plasma optical emission spectroscopy (ICP-OES; Thermo, iCAP 6300 Duo, Thermo Fisher Scientific GmbH, Berlin, Germany). Before measurement the particles were dissolved with $6 \mathrm{M} \mathrm{HCl}$.

The $\mathrm{cOxyHb}$ concentration in the $\mathrm{Hb}-\mathrm{MP}$ was determined indirectly by the oxygen release method as described above for the RBC suspensions.

MetHb-MP were prepared as follows: Hb-MP suspensions (PPV 10\%) were incubated with $5 \mathrm{mM}$ $\mathrm{NaNO}_{2}$ solution in PBS pH 7.4 for 30 min under gentle mixing at room temperature $\left(22^{\circ} \mathrm{C}\right)$ and stored overnight at $4{ }^{\circ} \mathrm{C}$. The MetHb-MP were washed three times with PBS (pH 7.4) and finally resuspended in PBS to a PPV of $10 \%$.

\subsection{NMR Analysis}

For the relaxivity measurements, $\mathrm{Hb}$ and $\mathrm{MetHb}$ solution samples were prepared at $\mathrm{cHb}$ of $30 \mathrm{mg} / \mathrm{mL}$ in PBS pH 7.4. Different MetHb content was obtained by mixing Hb solution with MetHb solution at the ratios 100/0, 80/20, 60/40, 40/60, 20/80, and 0/100. All mixed Hb samples were diluted with PBS pH 7.4 to obtain solutions with different $\mathrm{cHb}$ and $\mathrm{cMetHb}$.

The Hct of fresh RBC and MetHb-RBC suspensions was adjusted to $10 \%$ and then these suspensions were mixed at ratios 100/0, 80/20,60/40, 40/60, 20/80, and 0/100 to obtain suspensions with different $\mathrm{MetHb}$ concentrations. Each mixed RBC sample was diluted with PBS pH 7.4 to Hct of $2 \%$ and $5 \%$. GA-RBCs prepared with the different GA concentrations listed above were also diluted to Hct of $2 \%$ and 5\% with PBS $\mathrm{pH} 7.4$.

The Hb-MP and MetHb-MP suspensions (PPV 10\%) were mixed at ratios 100/0, 80/20, 60/40, $40 / 60,20 / 80$, and 0/100 to obtain different MetHb concentrations in the particle suspensions. Then all mixed samples were diluted with PBS pH 7.4 to obtain suspensions with PPV of $2 \%, 4 \%$, and $6 \%$. HSA-MP cross-linked with different GA concentrations were also suspended in PBS pH 7.4 to PPV of $2 \%, 4 \%$, and $6 \%$.

A total of $1 \mathrm{~mL}$ of each sample was transferred into nuclear magnetic resonance (NMR) glass tube (7.5 mm inner diameter). Longitudinal relaxation time $\left(\mathrm{T}_{1}\right)$ and transverse relaxation time $\left(\mathrm{T}_{2}\right)$ were obtained by using a $0.94 \mathrm{~T}$ Minispec mq40 relaxometer (Bruker Analytik, Rheinstetten, Germany) operated at a proton frequency of $40 \mathrm{MHz}$ and a preset temperature of $37^{\circ} \mathrm{C}$. The relaxation rates $1 / T_{1}$ or $1 / T_{2}$ were plotted versus concentration of the samples. The relaxivities $\left(r_{1}, r_{2}\right)$ were obtained from the slope of the linear regression of the relaxation rate plot $\left(1 / T_{i} ; i=1,2\right)$ versus concentration of investigated compound.

$$
r_{i}=\left[\frac{1}{T_{i}}-\frac{1}{T_{i}^{0}}\right] \frac{1}{c} ; i=1,2
$$

with $c$ being the concentration, $T_{i}^{0}$ the relaxation time of the solvent without samples, and $T_{i}$ the longitudinal $(i=1)$ or transverse $(i=2)$ relaxation time of the samples. 
Supplementary Materials: Supplementary Materials can be found at http://www.mdpi.com/1422-0067/21/23/ 8978/s1. Figure S1: OxyHb concentration in $\mathrm{Hb}$-solutions at various MetHb concentration (total Hb concentration, $\mathrm{cHb}, 30 \mathrm{mg} / \mathrm{mL}$ in all solutions, orange squares) and in mixtures of fresh RBC with MetHb-RBC suspensions (Hct $10 \%$ in all suspensions, blue circles) determined by oxygen release method and blood gas analyzer $(\mathrm{N}=6)$; Figure S2: Relaxation rates of human and bovine RBC (vital and GA-cross-linked) in dependency on the total $\mathrm{Hb}$ concentration.

Author Contributions: Conceptualization, H.B., E.S. and W.K.; methodology, W.K., E.S., A.S., Y.X.; validation, H.B., R.G. and W.K.; formal analysis, W.K.; investigation, W.K., N.S. and C.K.; data curation, R.G. and A.P.; writing-original draft preparation, W.K. and R.G.; writing-review and editing, R.G. and H.B.; supervision, H.B., R.G. and E.S.; funding acquisition, H.B. All authors have read and agreed to the published version of the manuscript.

Funding: This research was funded by an academic development scholarship from Payap University (W.K.) and the University of Phayao (N.S. and C.K.), by Horizon 2020-MSCA-RISE 2018, Oxigenated (823879). We acknowledge support from the German Research Foundation (DFG) and the Open Access Publication Funds of Charité-Universitätsmedizin Berlin and the Hans-Joachim Hoster Foundation.

Conflicts of Interest: The authors declare no conflict of interest.

\section{References}

1. Antonini, E.; Brunori, M. Hemoglobin. Annu. Rev. Biochem. 1970, 39, 977-1042. [CrossRef]

2. Riggs, A. Functional properties of hemoglobins. Physiol. Rev. 1965, 45, 619-673. [CrossRef] [PubMed]

3. Mansouri, A. Methemoglobinemia. Am. J. Med. Sci. 1985, 289, 200-209. [CrossRef] [PubMed]

4. White, J.C.; Beaver, G.H. A review of the varieties of human haemoglobin in health and disease. J. Clin. Pathol. 1954, 7, 175-200. [CrossRef] [PubMed]

5. Bodansky, O. Methemoglobinemia and methemoglobin-producing compounds. Pharmacol. Rev. 1951, 3, $144-191$.

6. Benz, E.J.; Ebert, B.L. Hemoglobin Variants Associated With Hemolytic Anemia, Altered Oxygen Affinity, and Methemoglobinemias. In Hematology: Basic Principles and Practice; Elsevier Inc.: Amsterdam, The Netherlands, 2018; pp. 608-615. ISBN 9781455740413.

7. Brunelle, J.A.; Degtiarov, A.M.; Moran, R.F.; Race, L.A. Simultaneous measurement of total hemoglobin and its derivatives in blood using CO-oximeters: Analytical principles; Their application in selecting analytical wavelengths and reference methods; A comparison of the results of the choices made. Scand. J. Clin. Lab. Investig. 1996, 56, 47-69. [CrossRef]

8. Whitehead, R.D.; Mei, Z.; Mapango, C.; Jefferds, M.E.D. Methods and analyzers for hemoglobin measurement in clinical laboratories and field settings. Ann. N. Y. Acad. Sci. 2019, 1450, 147. [CrossRef]

9. Haymond, S.; Cariappa, R.; Eby, C.S.; Scott, M.G. Laboratory Assessment of Oxygenation in Methemoglobinemia. Clin. Chem. 2005, 51, 434-444. [CrossRef]

10. Cortazzo, J.A.; Lichtman, A.D. Methemoglobinemia: A review and recommendations for management. J. Cardiothorac. Vasc. Anesth. 2014, 28, 1043-1047. [CrossRef]

11. Xiong, Y.; Liu, Z.Z.; Georgieva, R.; Smuda, K.; Steffen, A.; Sendeski, M.; Voigt, A.; Patzak, A.; Bäumler, H. Nonvasoconstrictive Hemoglobin Particles as Oxygen Carriers. ACS Nano 2013, 7, 7454-7461. [CrossRef]

12. Kloypan, C.; Prapan, A.; Suwannasom, N.; Chaiwaree, S.; Kaewprayoon, W.; Steffen, A.; Xiong, Y.; Baisaeng, N.; Georgieva, R.; Bäumler, H. Improved oxygen storage capacity of haemoglobin submicron particles by one-pot formulation. Artif. Cells Nanomed. Biotechnol. 2018, 46, S964-S972. [CrossRef] [PubMed]

13. Xiong, Y.; Georgieva, R.; Steffen, A.; Smuda, K.; Bäumler, H. Structure and properties of hybrid biopolymer particles fabricated by co-precipitation cross-linking dissolution procedure. J. Colloid Interface Sci. 2018, 514, 156-164. [CrossRef] [PubMed]

14. Bäumler, H.; Xiong, Y.; Liu, Z.Z.; Patzak, A.; Georgieva, R. Novel Hemoglobin Particles-Promising New-Generation Hemoglobin-Based Oxygen Carriers. Artif. Organs 2014, 38, 708-714. [CrossRef] [PubMed]

15. Eike, J.H.; Palmer, A.F. Effect of glutaraldehyde concentration on the physical properties of polymerized hemoglobin-based oxygen carriers. Biotechnol. Prog. 2004, 20, 1225-1232. [CrossRef]

16. Prapan, A.; Suwannasom, N.; Kloypan, C.; Chaiwaree, S.; Steffen, A.; Xiong, Y.; Kao, I.; Pruß, A.; Georgieva, R.; Bäumler, H. Surface Modification of Hemoglobin-Based Oxygen Carriers Reduces Recognition by Haptoglobin, Immunoglobulin, and Hemoglobin Antibodies. Coatings 2019, 9, 454. [CrossRef]

17. Gomori, J.M.; Grossman, R.I.; Yu-Ip, C.; Asakura, T. NMR relaxation times of blood: Dependence on field strength, oxidation state, and cell integrity. J. Comput. Assist. Tomogr. 1987, 11, 684-690. [CrossRef] 
18. Aime, S.; Dastrú, W.; Fasano, M.; Arnelli, A.; Castagnola, M.; Giardina, B.; Ascenzi, P. Quantitative determination of methemoglobin by measuring the solvent-water proton-nuclear magnetic resonance relaxation rate. Clin. Chem. 1992, 38, 2401-2404. [CrossRef]

19. Tentori, L.; Salvati, A.M. Hemoglobinometry in Human Blood. Methods Enzymol. 1981, 76, 707-715. [CrossRef]

20. Bass, J.; Sostman, H.D.; Boyko, O.; Koepke, J.A. Effects of cell membrane disruption on the relaxation rates of blood and clot with various methemoglobin concentrations. Investig. Radiol. 1990, 25, 1232-1237. [CrossRef]

21. Thulborn, K.R.; Waterton, J.C.; Matthews, P.M.; Radda, G.K. Oxygenation dependence of the transverse relaxation time of water protons in whole blood at high field. BBA Gen. Subj. 1982, 714, 265-270. [CrossRef]

22. Păltineanu, B.; Voinea, S. Spin-spin proton transverse relaxation times studies of red blood cell membrene in rabbits with experimental atherosclerosis. Anim. Sci. 2017, 60, 174-182.

23. Stefanovic, B.; Pike, G.B. Human whole-blood relaxometry at 1.5T: Assessment of diffusion and exchange models. Magn. Reson. Med. 2004, 52, 716-723. [CrossRef] [PubMed]

24. Gupta, A.; Kumar, P. Assessment of the histological state of the healing wound. Plast. Aesthetic Res. 2015, 2, 239. [CrossRef]

25. Koenig, S.H.; Brown, R.D.; Lindstrom, T.R. Interactions of solvent with the heme region of methemoglobin and fluoro-methemoglobin. Biophys. J. 1981, 34, 397-408. [CrossRef]

26. La Mar, G.N.; Chatfield, M.J.; Peyton, D.H.; de Ropp, J.S.; Smith, W.S.; Krishnamoorthi, R.; Satterlee, J.D.; Erman, J.E. Solvent isotope effects on NMR spectral parameters in high-spin ferric hemoproteins: An indirect probe for distal hydrogen bonding. Biochim. Biophys. Acta (BBA)/Protein Struct. Mol. 1988, 956, 267-276. [CrossRef]

27. Brooks, R.A.; Di Chiro, G.; Patronas, N. MR imaging of cerebral hematomas at different field strengths: Theory and applications. J. Comput. Assist. Tomogr. 1989, 13, 194-208. [CrossRef]

28. Bäumler, H.; Halbhuber, K.J.; Stibenz, D.; Lerche, D. Topo-optical investigations of human erythrocyte glycocalyx conformational changes induced by dextran. BBA Gen. Subj. 1987, 923, 22-28. [CrossRef]

29. Morel, F.M.M.; Baker, R.F.; Wayland, H.; Knust-Graichen, P.V. Quantitation of human red blood cell fixation by glutaraldehyde. J. Cell Biol. 1971, 48, 91-100. [CrossRef]

30. Folland, R.; Steven, J.H.; Charlesby, A. Proton spin relaxation in liquid polydimethylsiloxane: Molecular motion and network formation. J. Polym. Sci. Polym. Phys. Ed. 1978, 16, 1041-1057. [CrossRef]

31. Chen, E.-L.; Kim, R.J. Magnetic Resonance Water Proton Relaxation in Protein Solutions and Tissue: T1@ Dispersion Characterization. PLoS ONE 2010, 5, e8565. [CrossRef]

32. Charlesby, A. The use of pulsed NMR techniques in the measurement of radiation effects in polymer. Radiat. Phys. Chem. 1979, 14, 919-930. [CrossRef]

33. Xiong, Y.; Steffen, A.; Andreas, K.; Müller, S.; Sternberg, N.; Georgieva, R.; Bäumler, H. Hemoglobin-based oxygen carrier microparticles: Synthesis, properties, and in vitro and in vivo investigations. Biomacromolecules 2012, 13, 3292-3300. [CrossRef] [PubMed]

34. Ansari, F.A.; Ali, S.N.; Mahmood, R. Sodium nitrite-induced oxidative stress causes membrane damage, protein oxidation, lipid peroxidation and alters major metabolic pathways in human erythrocytes. Toxicol. Vitr. 2015, 29, 1878-1886. [CrossRef]

35. Keszler, A.; Piknova, B.; Schechter, A.N.; Hogg, N. The reaction between nitrite and oxyhemoglobin: A mechanistic study. J. Biol. Chem. 2008, 283, 9615-9622. [CrossRef] [PubMed]

36. Haldane, J. The ferricyanide method of determining the oxygen capacity of blood. J. Physiol. 1900, 25, 295-302. [CrossRef]

37. Cook, S.F. The action of potassium cyanide and potassium ferricyanide on certain respiratory pigments. J. Gen. Physiol. 1928, 11, 339-348. [CrossRef] [PubMed]

Publisher's Note: MDPI stays neutral with regard to jurisdictional claims in published maps and institutional affiliations. 